\title{
The Role of Remote Sensing and GIS for Locating Suitable Mangrove Plantation Sites along the Southern Saudi Arabian Red Sea Coast
}

\author{
Ibrahim H. Elsebaie, Ayman S. H. Aguib, Dafer Al Garni \\ Civil Engineering Department, College of Engineering, King Saud University, Riyadh, KSA \\ Email: elsebaie@ksu,edu.sa, aaguib@ksu,edu.sa,dalgarni@ksu.edu.sa
}

Received November 28, 2012; revised January 6, 2013; accepted February 5, 2013

\begin{abstract}
This paper investigated a methodology for locating suitable sites for establishing mangrove plantations along the south Saudi Arabian Red Sea coast based on Geological characteristics, geomorphology and discharge of drainage effluents as primary sitting criteria. Remote sensing Satellite imagery and digital elevation models were interpreted to determine most of the parameters, the rest were measured in field. In the study, it was found that some healthy mangrove stands now exist along the Red Sea coast near the city of Jizan although many stands have been destroyed in recent years due to rapid development, infilling and over-grazing and use of the mangroves as fuel. Remote sensing satellite imagery was used to map exiting Mangrove stands of different densities along the study area. The study determined that mangrove stands are primarily concentrated in the southern part of the study area and that they are sparsely found northward. Interpretation of A Landsat Thematic Mapper panchromatic band image and DEM showing that red sea coast along the study area are mainly covered by fans of ten drainage basins where the Flood potentiality of these basins was determined. The study was able to determine that three areas, which have a moderate to low flash flood potential, have the necessary environmental elements necessary to support mangroves. One, in particular, would be the best site to establish a mangrove plantation project.
\end{abstract}

Keywords: Mangroves; Remote Sensing; Geographic Information Systems; Digital Elevation Model

\section{Introduction}

Mangroves play a vital role in supporting the surrounding environment. Mangroves play an important role in controlling erosion and protecting the coastline. Along the Red Sea coast, mangrove stands are distributed. Since the mid-1980s, these stands have been threatened by rapid tourist development and grazing by Bedouins. The size and the number of these stands have been reduced and many of the stands have been destroyed completely $[1,2]$. Thus, it is necessary to conserve the existing mangroves stands and plant mangroves where ever they can be grown.

Mangroves protect shorelines from erosion by stabilizing sediments with their tangled root systems. They maintain water quality and clarity, filtering pollutants and trapping sediments originating from land. Mangroves function as nurseries for shrimp and recreational fisheries, exporters of organic matter to adjacent coastal food chains, and enormous sources of valuable nutrients [3].

Mangroves occur in sparse, but natural, formation along the Saudi Arabian Red Sea coast. Many more mangroves stands existed, but have been destroyed by factors such as overgrazing by Bedouins who use the trees as a fuel and, more recently, by development. Saifullah [4] presented an overview of various mangrove studies along the Red Sea coast of Saudi Arabia and concluded that information on the subject is inadequate.

There are many recent studies on the ecology of mangroves and setting up mangrove plantations $[5,6]$. The consensus of these authors is that mangroves are threatened around the world due to infilling and other forms of development and pollution.

There is a large body of scientific literature on using remote sensing for assessing the condition of mangroves [7-12]. Many other studies have used remote sensing for mapping mangroves and locating suitable sites for mangrove plantations as reported in [13-16].

The distribution of mangroves in both northern and southern Red Sea coast of Saudi Arabia is patchy and they do not occur as a continuous forest and are generally restricted to the low energy quieter environments. Mangroves occupy similar environments in both regions and are under similar stresses caused by various anthropo- 
genic activities and camel grazing. However, mangrove growth in south is relatively denser in comparison to north due mainly to the tropical climate, more wadis, higher rainfall and nutrients and less saline waters [2].

In this study, sites suitable for mangrove plantations along the southern Saudi Arabian Red Sea coast were identified. The study demonstrated the use of remote sensing and geographic information systems to identify suitable locations to establish mangrove plantations. The present study focused on the critical environmental factors necessary for successful mangrove plantation development.

\section{Geographical Location of the Study Area}

The study area lies between $16^{\circ} 01^{\prime} \mathrm{N}$ and $19^{\circ} 57^{\prime} \mathrm{N}$ and between $40^{\circ} 38^{\prime} \mathrm{E}$ and $43^{\circ} 55^{\prime} \mathrm{E}$ as shown in Figure 1. Jizan city lies in the western southern part of the kingdom of
Saudi Arabia on the Red Sea Coast; this city is characterized by rainfall storms which are varying in intensity and duration. The southern part of the city is sometimes exposed to the risk of flash flooding due to the heavy rainfall intensity which may happen during the rainy storms, the peak runoff flows from the East towards West.

The highest concentrations of mangroves are found near the coastal city of Jizan. North and south of Jizan are long stretches of coastline barren of any type of vegetation and stretches with relatively small patches of mangroves.

Jizan has great tourism potential owing to the abundance of near-shore coral reefs, natural mangroves and beautiful oasis. The Farasan Islands which as $40 \mathrm{~km}$ from Jizan, are a protected series of coral islands and are habitat to endangered species of many animals. Jizan has grown from a village of fewer than 10,000 people in

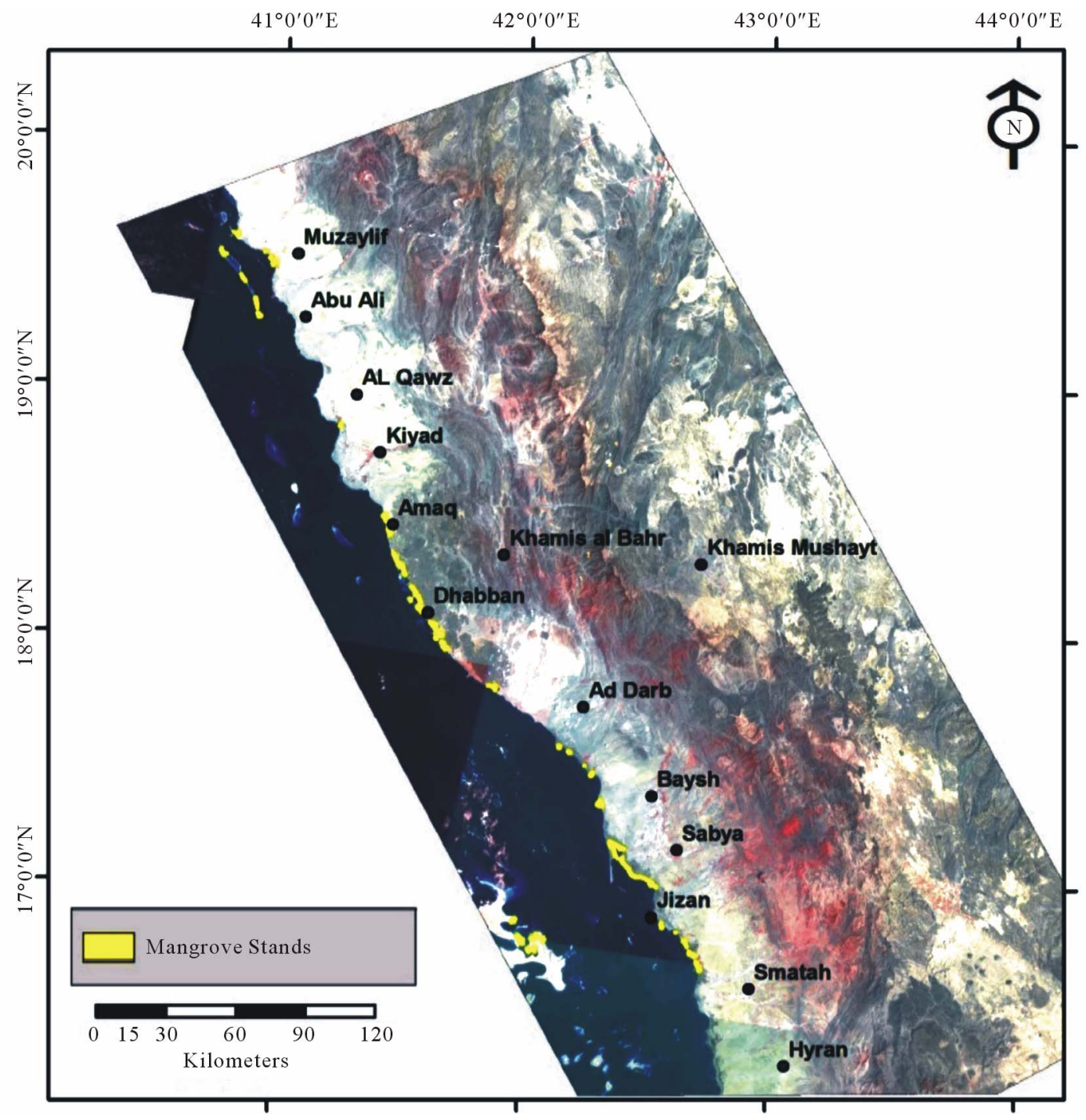

Figure 1. Mangrove stands as interpreted from GeoEye images showing location of the study area. 
1978 to over 100,000 by 2008 and so care must be taken to protect the mangroves from development.

\section{Materials and Methods}

The six critical environmental factors that determine if a coastline is capable of starting and maintaining a mangrove plantation are: 1) air temperature; 2) water temperature; 3) water salinity; 4) tidal and wave energy; and 5) flood risk; and 6) soil type and stability [17]. The suitability value ranging for these environmental parameters are:

Air temperature: 8 - 47 degrees C; Water temperature: 22 - 34 degrees C; Water salinity: 33.8\%; Wave and tide energy: low; Flood potential: low; and Soil type: Sandy to sandy loam. With these environmental boundaries in mind, the objective was to determine where, if anywhere, on the southern Saudi Arabian Red Sea coast these environmental requirements were met.

\subsection{Existing Mangrove Stands and Primary Selection of the Sites}

The existing Mangrove Stands along as interpreted from GeoEye satellite images of the period 2005 to 2008 by visual screen digitizing. The identified stands checked and corrected at the field. The Mangrove stands are shown in (Figure 1).

Mangrove can only grow in areas away from direct waves. Satellite images of the area extended along the Saudi Red Sea shoreline, starting from Saudi ArabiaYemen boundary up to $300 \mathrm{~km}$ north had been studied to define the coastal area protected from direct current waves. These areas include small bays or area protected from the waves by islands.

Ten locations meet the searching criterion were sited. All these locations already have mangrove stand(s) (See Figure 2). So that, in this study our objective will be, selecting the best suitable site for mangrove plantation

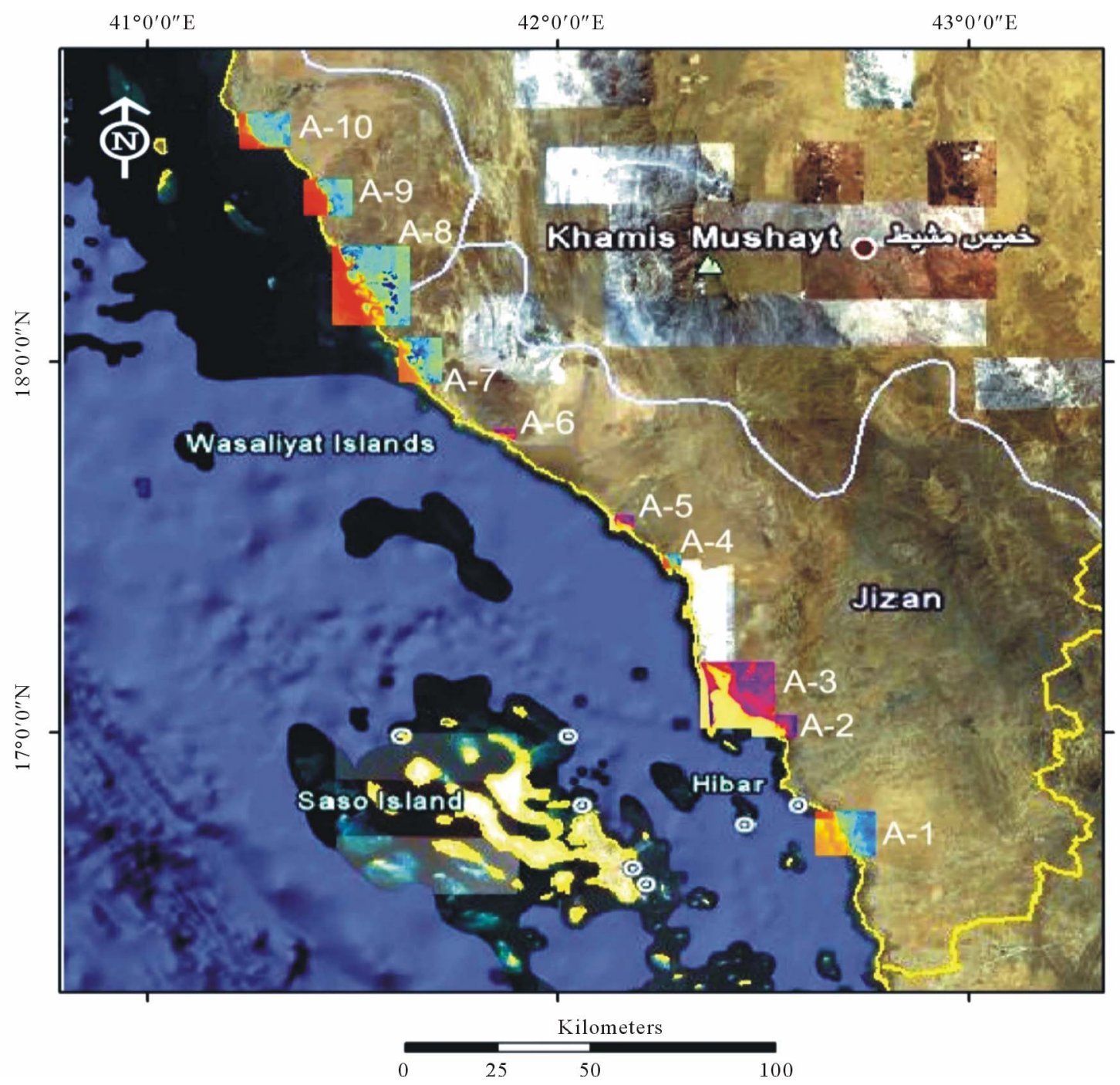

Figure 2. Location map of the ten sites protected from direct current waves in the study area. 
out of these ten locations instead of finding a new location. It is impossible to have Mangrove plantation project in open sea area. The best location for mangrove plantation project is the location with low mangrove density (not related to environmental aspects), good soil and away from urban area and basins with high flood potentiality.

\subsection{Water Temperature}

Data from the U.S. National Oceanographic and Atmo= spheric Administration (NOAA) on the average yearround near-shore sea temperature and salinity for the near-shore zone in the study area were obtained. Water temperature (surface) were derived from NOAA's Advanced Very High Resolution Radiometer (AVHRR) satellite which is accurate to within 0.5 degrees C. Avicenna marina, the dominant mangroves species naturally found in the Red Sea coast requires relatively warm water [18].

The average sea surface temperature of the study area ranges between $26^{\circ} \mathrm{C}$ in winter and $32^{\circ} \mathrm{C}$ in summer is suitable for mangroves. The temperature varies by approximately $2^{\circ} \mathrm{C}$ between the north and south boundary of the study area. So, temperature is not an important factor in site selection in this study.

\subsection{Air Temperature}

Mangroves tolerate air temperatures as low as 8 degrees $\mathrm{C}$ for short periods of time and as high as 42 degrees $\mathrm{C}$ [18]. They thrive in the 28 degree to 30 degree temperature range. Data was obtained from the Presidency of Meteorology and Environment, Kingdom of Saudi Arabia for meteorological data including monthly air temperature for the months of January and August, representing the coldest and the hottest months, respectively, were obtained for the years 1999-2010. The lowest recorded temperature for the study area was 20 degrees $\mathrm{C}$ and the highest was 36 degrees $\mathrm{C}$. These temperature extremes are well within the range tolerated by mangroves.

\subsection{Salinity}

The Red Sea is one of the most saline bodies of water in the world, due to high evaporation. Salinity ranges from between 36 ppt in the southern part due to the effect of the Gulf of Aden water and reaches 41 ppt in the northern part, due mainly to the Gulf of Suez water and the high evaporation. The average salinity is 40 .

Mangrove trees are relatively tolerant of salt. They are able to withstand concentrations of up to $39 \mathrm{ppt}$ (part per thousands) and thrive in concentrations of about $36 \mathrm{ppt}$ [19].
The average salinity concentration for the study area, according to NASA [20] is between $36 \%$ to $38 \%$. Therefore, salinity is not a limiting factor for mangroves.

The southern part of the study area has lower salinity (36\% to 37\%) than the northern part (37\% to $38.5 \%$ ). Although salinity is suitable for Mangrove all over the study area, but Mangroves can grow better in the southern part that has a lower salinity, this might explain the high dense Mangrove stands existing in Gizan area.

\subsection{Remote-Sensing and GIS Applications}

Data for GIS were based on existing available sources in the study area that include satellite images acquired on different dates. Digitized map of the study area has been prepared. Multiple resource uses data were collected during the field trips and were used as bases in the selection of training areas. Old records, management history and other information (during the field trips) were collected from government offices and local people. Geometric correction was performed with fourth order polynomial and the root mean square (RMS) for the ground control points (GCP). One of the Landsat ETM images which were used in the study is shown in (Figure 3).

The software ArcGIS was used to define the drainage network of the study area using USGS 7.5 minute (30- by 30-m data spacing) Digital Elevation Models (DEM's). The USGS 7.5-minute DEM cast on Universal Transverse Mercator (UTM) projection. A Landsat Thematic Mapper panchromatic band image was used to check and correct the drainage network produced by ArcGIS.

The River Tools software program was used to generate a grid of the drainage patterns of all of the basins in the study area. Using ArcGIS, the grid was converted into a shapefile. The shapefile was then used to determine the morphological features (i.e. order of each individual segment of the basin and its length, basin length, basin shape, drainage density, stream frequency and bifurcation ratio) of each watershed. These factors, in addition to basin slope were determined using a digital elevation model (DEM) and the three dimension models of the study area as shown in Figures $\mathbf{4}$ and 5. These models were critical in determining the basin's proneness to flash flooding.

Basin length is the length measured along the principal flow path from the watershed outlet to the basin boundary. It is a measure of the travel time of water through the basin. Basin shape indicates the path runoff will travel through various parts of the basin and where runoff will discharge from the outlet.

Drainage density and stream frequency are the total length and total number of the entire stream segments in a drainage basin divided by the total area of the drainage basin. High drainage density or/and stream frequency of 


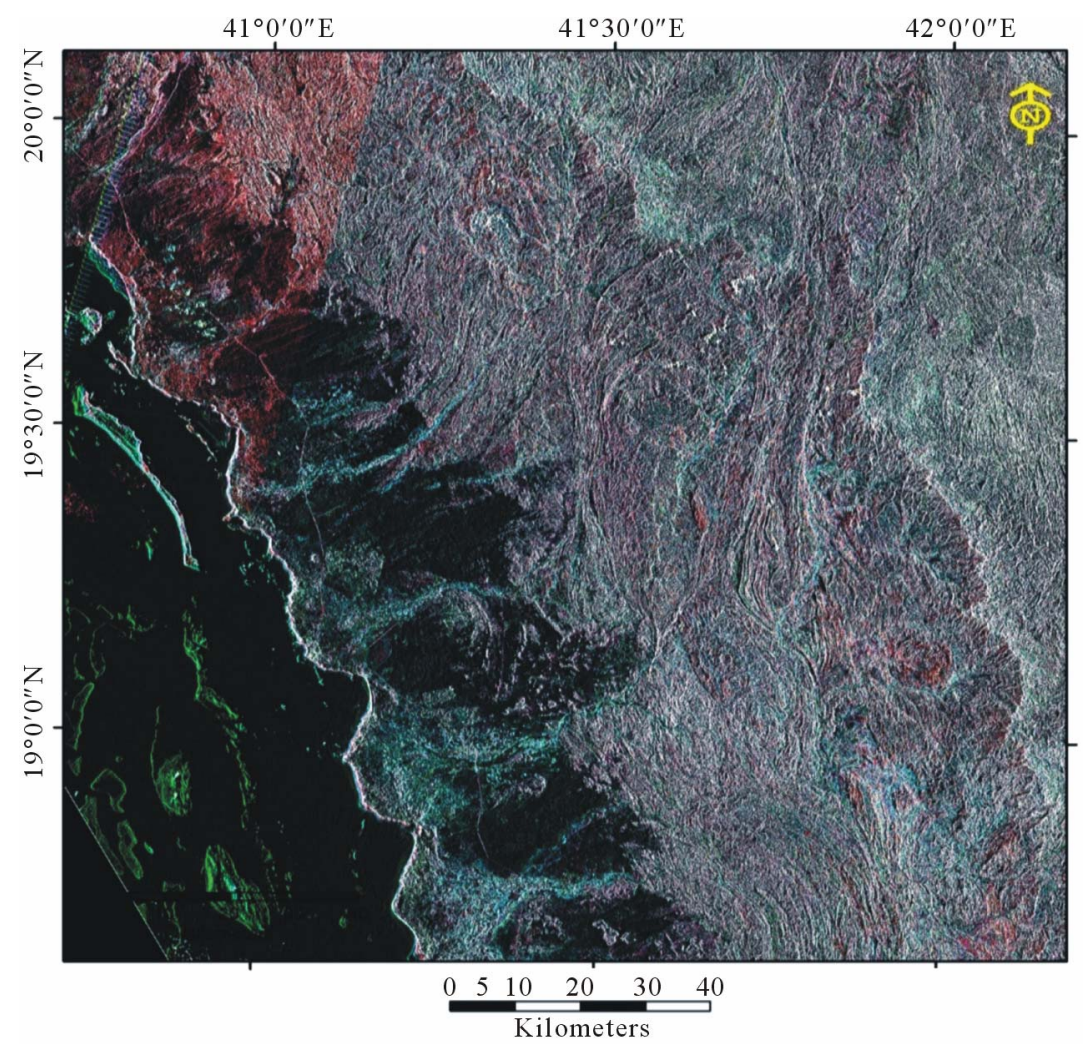

Figure 3. LANDSAT ETM images (bands 4, 3 and 2).

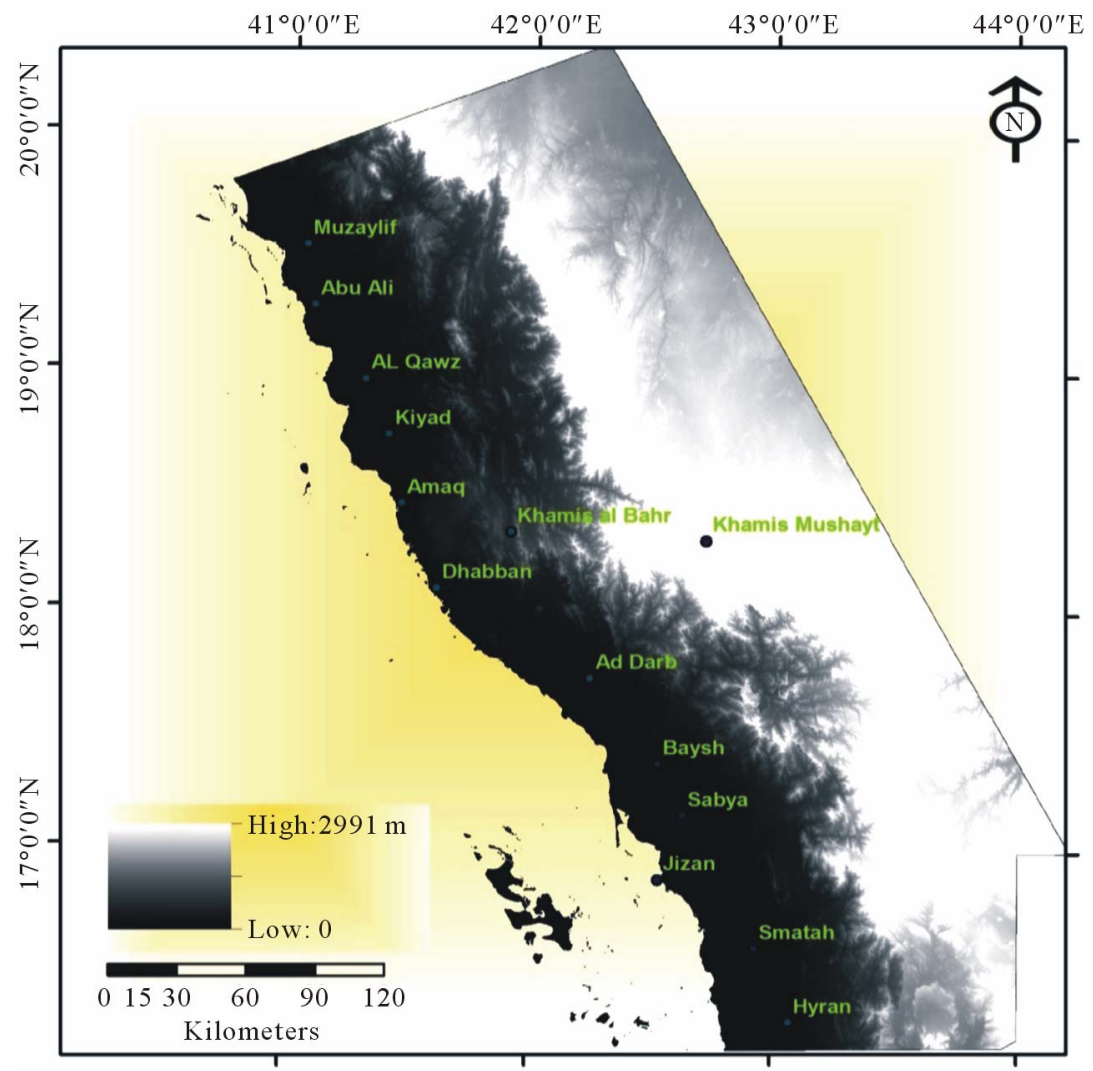

Figure 4. Digital elevation model of the study area. 


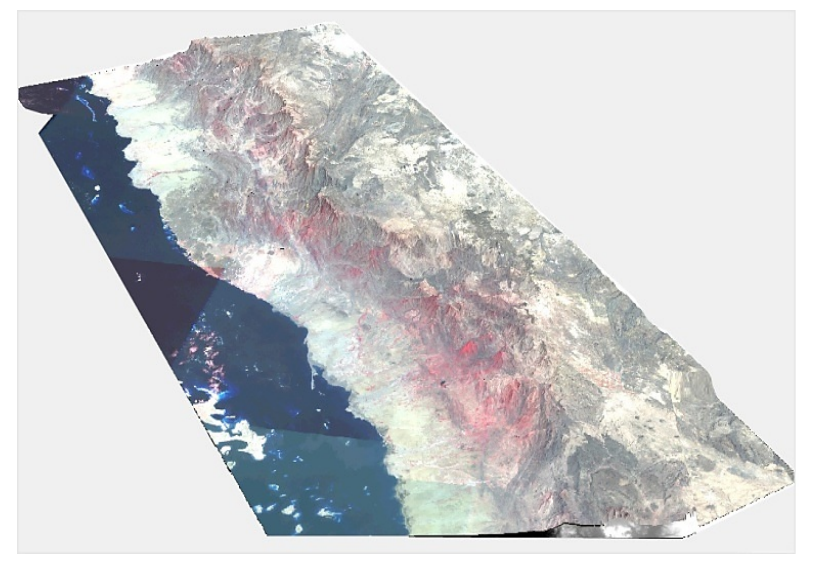

Figure 5. The three-dimension models of the study area.

a basin indicates a rapid storm response and conesquently high probability to result in a flash flood. The bifurcation ratio is the ratio of the number of streams of any order to the number of streams of the next highest order. A lower bifurcation ratio indicates a circular basin with high flood potentiality and visa a versa. In order to determine the bifurcation ratio, the steam order was determined for the entire segment in each basin using the Horton Law [21].

Basin slope is the average slope of a basin and is the most important variable affecting the momentum, speed and concentration of runoff. The possibility of starting a runoff event increases with increasing slope.

Some areas of the Saudi Arabian Red Sea coast are high wave energy zones due to their position with respect to the prevailing winds and also a lack of barrier islands which dissipate wave energy. They would be unsuitable locations for mangrove plantations. Other areas have barrier islands, protective bays and/or wide flat beaches which would be suitable from the wave perspective.

In order to identify zones along the study area that might have high wave energy, a three-dimension model of the study area was constructed. The model allowed us to identify zones with deltas with tidal creeks, small bays and channels with wide flat shores. These topographic conditions are correlated with low wave energy. The study area is classified into three classes with respect to wave energy: high, moderate or low as shown in (Figure 6).

\section{Results and Discussion}

Spot and GeoEye remote sensing satellite images that available for the study area were obtained. SPOT and GeoEye image were interpreted to map the existing mangrove stands. On GeoEye images, discrimination between different densities of mangroves was observed and mapped. Using the SPOT imagery, the presence or absence of mangroves was mapped.
The factors considered for suitability of a site for mangrove plantation were sea water surface temperature, seawater salinity, tidal and wave energy, flood risk potentiality, soil type, soil pH, soil salinity and soil texture. Salinity and surface water temperature were found suitable for Mangrove along the study area.

Flash floods pose a danger to young mangrove trees because they can cause the seedlings to uproot and carry them into the sea. Floods occur when precipitation falls too quickly on saturated soil or dry soil that has poor absorption ability due to its clay content. The runoff collects in low-lying areas and rapidly flows downhill. Flash floods occur in normally dry areas that have recently received precipitation, but may be seen anywhere downstream from the source of the precipitation, even many kilometers from the source. Flash floods are common in the arid plains of Saudi Arabia where there are large drainage basins that feed into one tertiary channel.

The best sites to actively seed mangrove plants are those that are sheltered from wave energy and have gently sloping foreshores. Optimum growth and establishment success appears to occur at one meter from the highest tidal zone down to the lowest tidal line. In Kuwait mangrove plantation project, the Bahrain ecotype of Avicennia marina-the species recommended for our area of study - the majority of the seedlings planted in the sandy area above the tidal line survived and produced spreading plants with luxuriant foliage and dense canopies. In contrast, only a handful of the seedlings survived below the tidal line and grew poorly [17].

Based on interpretation of the DEM and the calculations of basin length and shape, drainage density, stream frequency and bifurcation ratio, three basins with low wave energy and low flash flood potential were selected for being suitable for mangrove plantations. They were the Al-Ahsabah, Yabah and Kid basins and are shown in (Figure 6).

A number of basic soil parameters can be determined from these grain-size distribution.

Once three sites (Al-Ahsabah, Yabah and Kid) were selected based their and water temperature, salinity, low wave energy and low chance for flash flooding, soil samples were collected from each site. Coordinates for each sample location were determined using a survey- grade GPS. Four samples were taken at each site and divided into depth increments of $0-20,20 \mathrm{z}-40$, and $40-60 \mathrm{~cm}$.

Mangroves grow in soil with high sand content, low silt and clay fractions and low calcium carbonate content [17]. Soil characteristics for the study area are a function primarily of the type of local exposed rock and soil transported from the basins that drain to the Red Sea. In order to assess the capability of each basin with respect to soil, the following variables were assessed: Lineament 


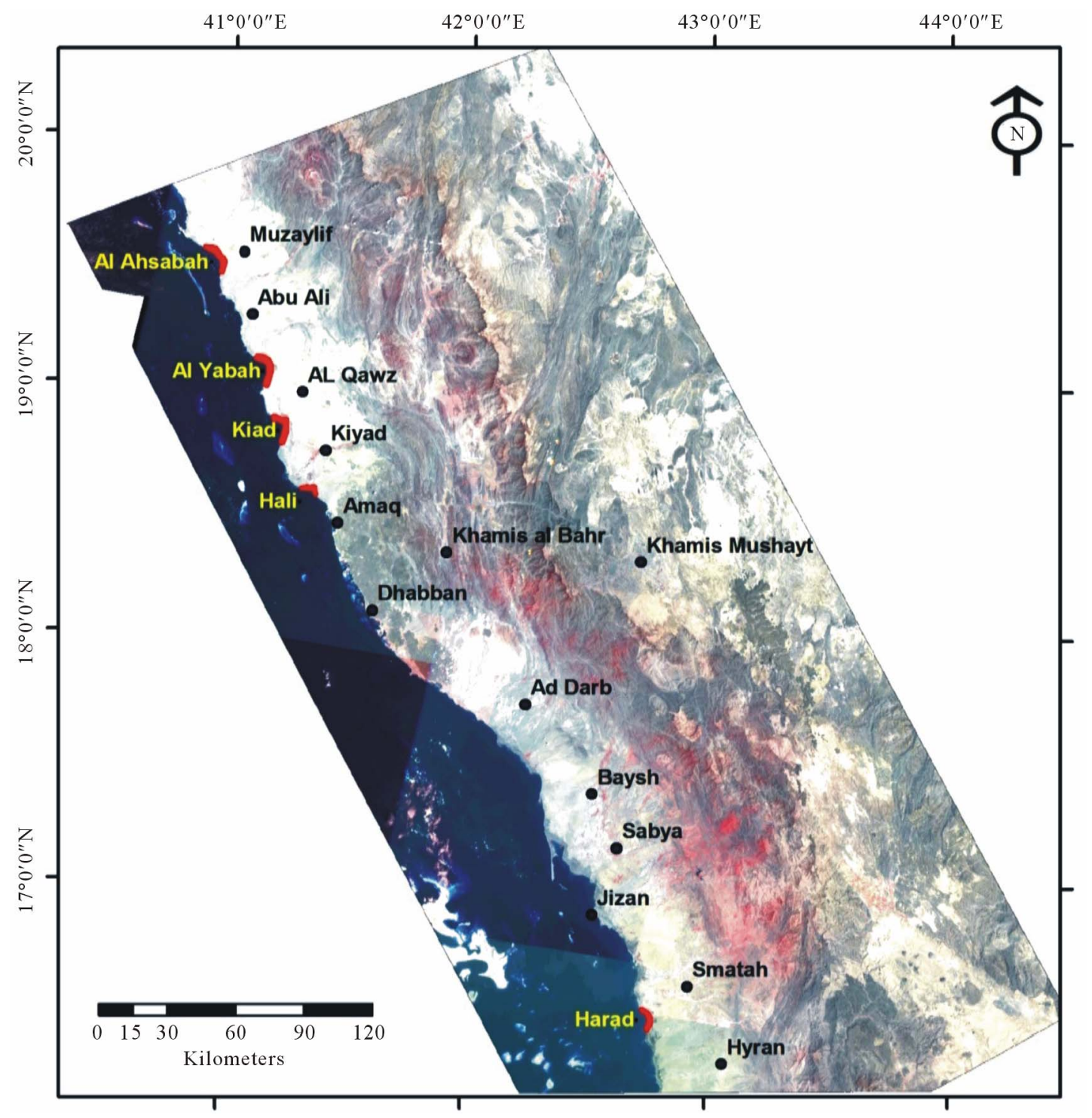

Figure 6. Areas with low wave and tide energy.

intensity; Drainage density; Area of exposed rocks and their mineral composition; Basin order; Basin bifurcation ratio; Drainage density; and Slope.

The formations and rock groups exposed on the surface were ranked based on the mineral composition of their rocks as: 1) very good; 2) good; 3) moderate; and 4) poor. The soil suitability factor (SSF) was determined for each exposed rock unit within the basin based on the variables assessed before.

The soil suitability factor was determined for each basin by averaging those of all rock unit exposed within the basin and then re-scaling the entire area in a range of between 1 and 100. The SSF was highest for the Yabah site. Therefore, based on all the criteria we measured and assessed, the Yabah site is the most suitable for establishing a mangrove plantation in the study area. Plan- tations could also be established at the other two sites, Al-Ahsabah and Kid, because they possess all the environmental characteristics required for mangroves.

\section{Conclusions}

Dense mangrove stands are found along the Red Sea coast in Jizan, some of these stands have been destroyed in recent years. This loss was the result due to development, infilling, tourist activities, over-grazing and use of the mangroves as fuel. There was limited evidence that the places where low-density mangrove stands now exist could not support high density stands of mangroves. Indeed, there was evidence that dense, healthy mangroves existed in these areas in the past and so could in the future.

Environmental factors, including temperature, salinity 
and rainfall also important key that have a large influence over the growth, survival and distribution on mangroves. Also Soil type is critical for successful or mangroves.

Selecting the sites suitable for mangrove plantation based on sea water surface temperature, seawater salinity, tidal and wave energy, flood risk potentiality, soil type, soil $\mathrm{pH}$, soil salinity and soil texture.

It can be seen from (Figure 7) that two basins have high flood potentiality Hali and Tashar. Although the rest of basins specially those of large areal extent such as Wadi Yabah, Al Ahsabah, and Qanunah have moderate to low flash flood potential. Therefore, the Hali and Harad sites are risky for flash floods that can destroy the mangrove propagules in the early plantation stage. Therefore, it is recommended to place the mangrove plantation site away from the main outlet of the basins of high flood potential, especially when it is accompanied with high slope such as Wadi Hali and Tashar. For that reason Hali and Harad sites were excluded from further assessment.

There are three sites in the study area suitable for establishing mangrove plantations. They are shown in (Figure 7). The Yabah basin is the best site of the three. It has all the physical characteristics required for successful mangrove growth.

The study found that remote sensing imagery was very useful for mapping critical features such as drainage pattern and existing mangrove stands. While these features could be mapped on the ground, remote sensing was far more efficient and accurate.

\section{Acknowledgements}

Funding by the long term comprehensive National Plan for Science, Technology and Innovation, KACST, for the

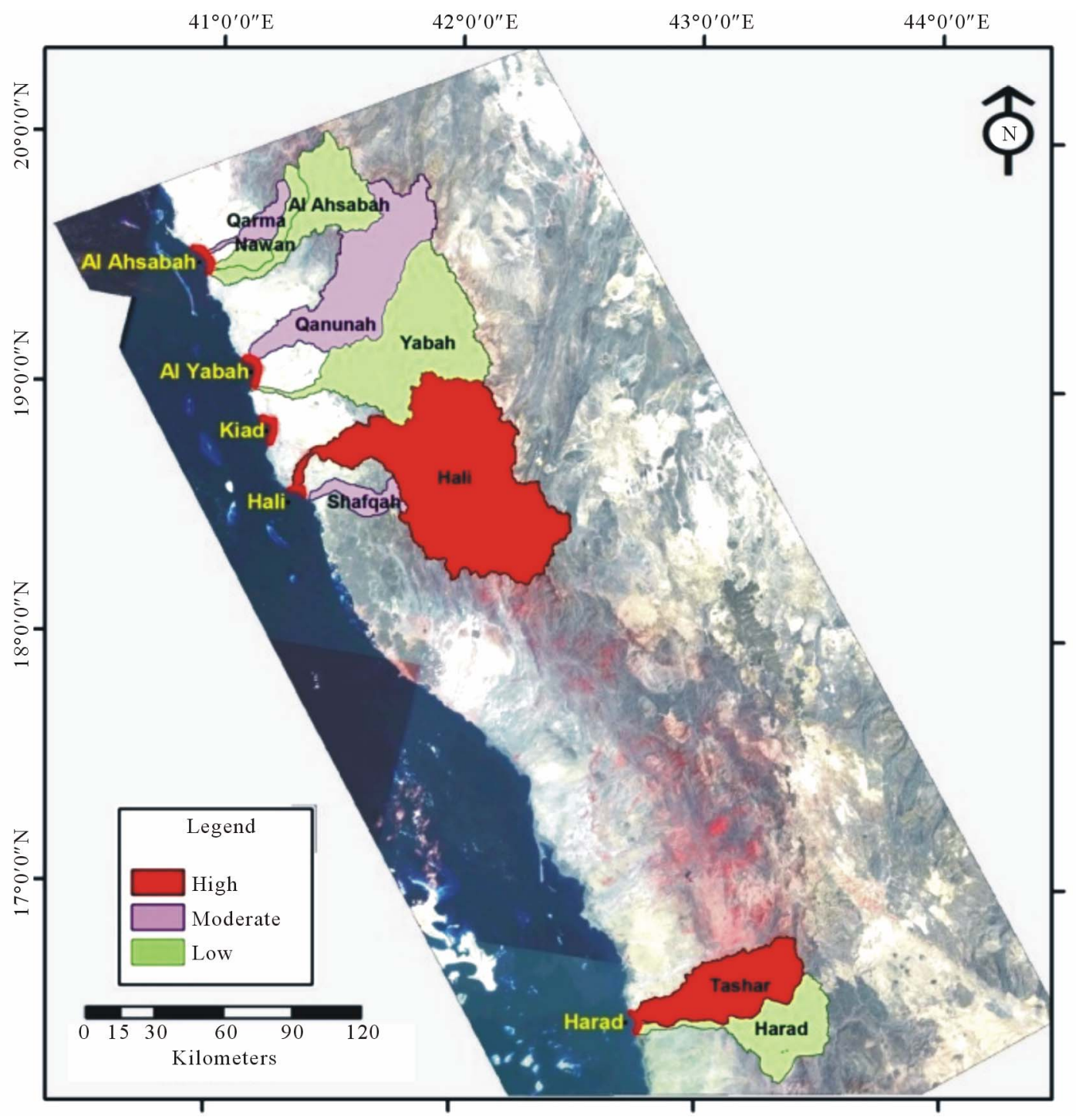

Figure 7. Flash flood potentiality. 
research is gratefully acknowledged. We are also grateful to the Environmental Affairs office in Jizan, and Hurghadah for their helpful information, the valuable photos and studies.

\section{REFERENCES}

[1] L. El-Juhany, "Present Status and Degradation Trends of Mangrove Forests on the Southern Red Sea Coast of Saudi Arabia," American-Eurasian Journal of Agricultural and Environmental Science, Vol. 6, No. 3, 2009, pp. 328-340.

[2] M. Khan, A. Kumar and A. Muqtadir, "Distribution of Mangroves along the Red Sea Coast of the Arabian Peninsula: Part 2. The Southern Coast of Western Saudi Arabia,” Journal Earth Science India, Vol. 3, 2010, pp. 154162.

[3] H. El Monsef and S. Smith, "Site Selection for Mangrove Plantations along the Egyptian Red Sea Coast," World Applied Sciences Journal, Vol. 3, No. 7, 2008, pp. 740747.

[4] S. M. Saifullah, "Mangrove Ecosystem of Saudi Arabian Red Sea Coast-An Overview," Journal of King Abdulaziz University, Marine Science, Special Issue on Red Sea Marine Environment, Vol. 7, 1996, pp. 263-270.

[5] R. Lewis, "Ecological Engineering for Successful Management and Restoration of Mangrove Forest,” Ecological Engineering, Vol. 24, No. 4, 2004, pp. 403-418.

[6] L. Gnanappazham, "Mangroves of Godavari-Anaylsis through Remote Sensing Approach,” Wetland Ecology and Management Journal, Vol. 8, No. 2, 2006, pp. 89-94.

[7] R. Krishnamoorthy, "Remote Sensing for the Assessment and Management of Mangroves: Indian Experience," Application of Remote Sensing and GIS for sustainable Development at National Remote Sensing Agency, Hyderabad, 1997.

[8] T., Kannan, T. Ajith Kumar and A. Duraisamy, "Remote Sensing for Mangrove Forest Management," CAS in Marine Biology, Annamalai University, Tamil Nadu, 2008.

[9] Y. Wang and A. Ngusaru, "Remote Sensing of Mangrove Change along the Tanzania Coast," Marine Geodesy, Vol. 26, No. 1-2, 2003, pp. 1-14. doi:10.1080/01490410306708

[10] S. Ongsomwang, A. Rangsipanich, S. Punkul and J. Suekuni, "Evaluating Mangrove Plantation Sites Using Remote Sensing and GIS in Surat Thani Province,” GIS/RS
Based Assessment of Mangrove Resources-Final Report, Bangkok, 2007, 47 p.

[11] M. Schwartz, “Mangroves: Remote Sensing,” Encyclopedia of Coastal Science, Vol. 2, Springer Publishers, Berlin, 2005, pp. 614-621.

[12] T. Truong, H. Pham, T. Thoab and L. Nguyen "Using Multi-Temproal Remote Sensing Data to Manage the Mangrove for Coastal Environmental Protection," The International Archives of the Photogrammetry, Remote Sensing and Spatial Information Sciences, Vol. 37, Beijing, 2008, pp. 709-711.

[13] E. Green, C. Clark, P. Mumby and A. Ellis, "Remote Sensing Techniques for Mangrove Mapping," International Journal of Remote Sensing, Vol. 19, No. 5, 1998, pp. 935-956. doi:10.1080/014311698215801

[14] T. Coleman, A. Mana and Y. Twumansi, "Application of Landsat to Study of Mangrove Ecology along the Coast of Ghana," Journal of the ISPRS, Vol. 49, 2008, pp. 362379.

[15] N. Azlan and R. Othman, "Monitoring of Mangrove Areas Using Remote Sensing toward Shoreline Protection," Proceedings of GIS Osrava, Malaysia, 2009.

[16] F. Howari, D. Jordan, N. Bouhauche and S. WyllieEcheverra, "Field and Remote Sensing Assessment of Mangrove Forests and Seagrass Beds in Northwest United Arab Emirates,” Journal of Coastal Research, Vol. 25, No. 1, 2009, pp. 48-56. doi:10.2112/07-0867.1

[17] N. Bhat and M. Suleiman, "Classification of Soils Supporting Mangrove Plantation in Kuwait," Archives of Agronomy and Soil Science, Vol. 50, No. 6, 2004, pp. 535- 551. doi:10.1080/03650340410001729726

[18] H. Teas, "Biology and Ecology of Mangroves,” W. Junk Publishers, The Hague, 1984, 188 p.

[19] N. Schmitz, V. Anouk, H. Beekman, J. Gitundu and N. Koedam, "Influence of a Salinity Gradient on the Vessel Characters of the Mangrove Species Rhizophora Mucronata,” Annals of Botany, Vol. 98, No. 6, 2006, pp. 13211330. doi:10.1093/aob/mcl224

[20] NASA, 2012.

http://science.nasa.gov/earth-science/oceanography/physi cal-ocean/salinity/

[21] D. Eash, “A Geographic Information System Procedure to Quantify Drainage-Basin Characteristics,” Journal of the American Water Resources Association, Vol. 30, No. 1, 2007, pp. 1-8. 